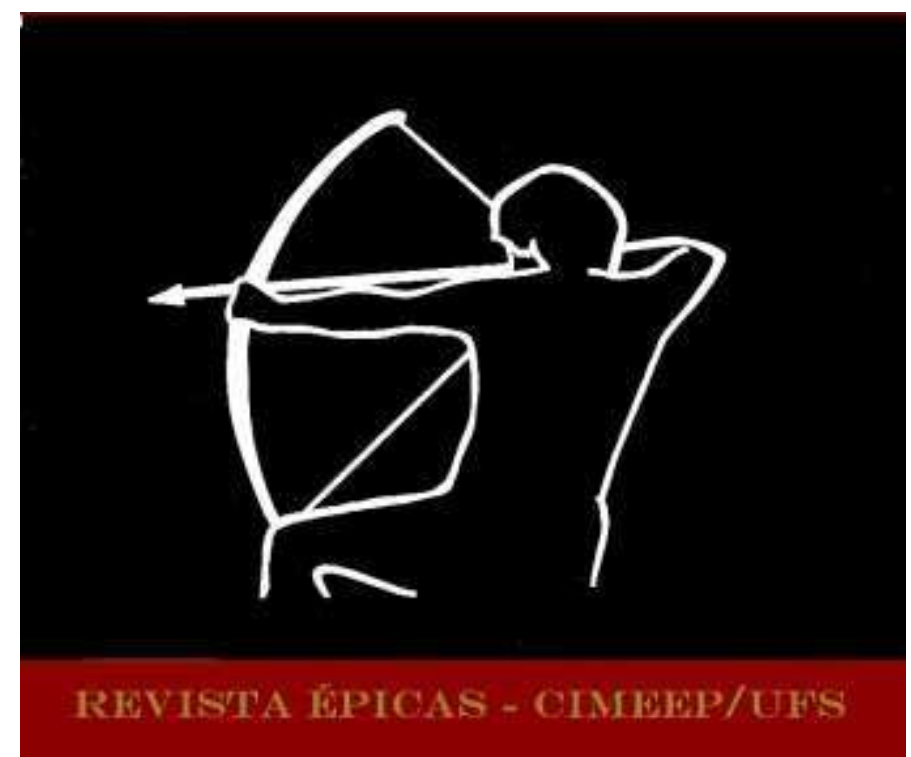

BISPO, Margarida Maria Araujo. A tradição oral na reprodução da epopeia clássica As Argonáuticas desde a colonização portuguesa dos capôs do rio Real à atual Tobias Barreto. In: Revista Épicas. Ano 4, N.

7, Jun 2020, p. 1-10. ISSN 2527-080-X.

\title{
A TRADIÇÃO ORAL NA REPRODUÇÃO DA EPOPEIA CLÁSSICA AS ARGONÁUTICAS DESDE A COLONIZAÇÃO PORTUGUESA DOS CAMPOS DO RIO REAL À ATUAL TOBIAS BARRETO
}

\author{
ORAL TRADITION IN THE REPRODUCTION OF CLASSIC EPIC POEM \\ THE ARGONAUTICA SINCE PORTUGUESE COLONIZATION \\ FROM THE FIELDS OF RIO REAL TO THE CURRENT TOBIAS BARRETO
}

Margarida Maria Araujo Bispo ${ }^{1}$

RESUMO: O artigo aborda a importância da tradição oral na preservação da epopeia épica clássica $A s$ Argonáuticas de Apolônio de Rhodes, dando ênfase à "lenda do Carneiro de Ouro" existente na Serra do Canine, no município de Tobias Barreto, Sergipe. Dimensionarei como a contação de histórias dialoga com o aspecto mítico que foi gerado a partir da tradição oral e consequentemente contribui para a preservação da história dos argonautas até os dias atuais por meio dessa lenda, contada nas imediações da Serra do Canine e na própria sede do município, a cidade de Tobias Barreto.

Palavras-chave: As Argonáuticas; Lenda do Carneiro de Ouro; oralidade, Serra do Canine; epopeia clássica.

ABSTRACT: The article discusses the importance of oral tradition in the preservation of the classic epic poem The Argonautica of Apolônio de Rhodes, emphasizing the "legend of the Golden Sheep" in the Serra do Canine, in the municipality of Tobias Barreto, Sergipe. I will dimension how the storytelling dialogues with the mythical aspect that was generated from the oral tradition and consequently contributes to the preservation of the history of the Argonauts until the present day through this legend, told in the vicinity of Serra do Canine and in the headquarters of the municipality, the city of Tobias Barreto.

Keywords: The Argonautica; Legend of the Golden Sheep; orality, Serra do Canine; classic epic.

\footnotetext{
1 Professora da Rede pública Estadual e Municipal, graduada em Letras/Português pela Universidade Federal de Sergipe, pós-graduada em Planejamento Educacional pela Universidade Salgado de Oliveira, mestra em Literatura e Recepção pela Universidade Federal de Sergipe (2020).
} 


\section{Introdução}

Neste artigo, abordarei questões relativas à oralidade, observando-a, em especial, como uma fonte de preservação da epopeia clássica As Argonáuticas no contexto sergipano, especificamente nos povoados Campestre do Abreu, Jebeberi, Cancelão e Agrovila, situados nas imediações da Serra do Canine, na cidade de Tobias Barreto no estado de Sergipe. O objetivo dessa abordagem é comprovar como a oralidade tem sido responsável pela preservação de $A s$ Argonáuticas em comunidades que não possuíam nenhum contato com obras clássicas e que, sem saber, possuem em sua “lenda” local uma parte da Literatura Clássica.

Pretendo, na abordagem, destacar a importância da contação da história, refletindo sobre como o mito presente na epopeia clássica As Argonáuticas de Apolônio de Rhodes passa a ser um conhecido por agricultores analfabetos ao longo dos anos nos rincões da Serra do Canine no interior de Sergipe e em outras localidades de Minas Gerais. Nesse sentido, é notório que a oralidade foi o principal meio para que esse fenômeno pudesse acontecer, pois foi através dela que a perpetuação da história se fez - e ainda se faz - presente nessas comunidades. Todavia, para que esta realidade pudesse acontecer, foi necessário que a epopeia pudesse chegar aos ouvidos da população e, nesse sentido, destaco a influência portuguesa deixada por Belchior Dias Moreira², o Moréia, e seus seguidores por ocasião da colonização das terras que hoje abrangem o território da cidade de Tobias Barreto, no interior de Sergipe.

Apesar de citar o estado de Minas Gerais como um espaço por onde a lenda do Carneiro de Ouro também circula, meu foco aqui se restringirá às terras que abrangem a Serra do Canine e às reflexões sobre como os habitantes dessas localidades permaneceram fiéis às histórias contadas por seus ancestrais ao longo dos séculos.

\section{Sobre As Argonáuticas e suas fragmentações lendárias nos povoados Campestre do Abreu, Jabeberi, Cancelão e Agrovila}

As Argonáuticas nos trazem personagens da mitologia grega que saem de Cólquida, com Jasão, em busca do Velocino de Ouro. De acordo com as lendas encontradas na mitologia grega, os chamados "argonautas" faziam parte de uma expedição que buscava o Velocino de Ouro, ou seja, a lã de ouro de um carneiro alado mandado por Zeus para salvar Frixo e Hele quando a mãe de ambos, Atamas, quis sacrificá-los.

Sobre o herói Jasão, o principal argonauta, a história nos conta que, quando Éson foi destronado por Pélias, seu filho Jasão teria retornado logo após atingir a maioridade para

\footnotetext{
2 “Aparece como ciudadano de Bahia en 1595, como uno de los que solicitó a la Corona los mismos derechos que habia tenido Gabriel Soares de Sousa para explotar las tierras del rio Sao Francisco" (SCHWARTZ, 1973, p. 127).
} 
retomar o trono que a ele pertencia. Para livrar-se da ameaça de Jasão, Pélias ordena ao jovem que vá em busca do Velocino de Ouro, plano pensado pelo usurpador para eliminar o jovem pretendente ao trono. Para realização da tarefa, um mensageiro andou por toda a Grécia para convocar heróis interessados em participar da empreitada. Ao fim da jornada desse arauto, cerca de 50 jovens heróis de grande valor e renome se apresentaram para cumprir a tarefa. Cada um deles levou, para a jornada desconhecida, suas habilidades específicas para auxiliar na expedição. Argos, filho de Frixo, constrói o navio que levará os jovens e, por esse motivo, a embarcação recebe o nome de Argo e seus tripulantes ficam conhecidos como argonautas.

A primeira escala da aventura foi na ilha de Lemnos, habitada somente por mulheres. Os argonautas chegaram à ilha, e lá permaneceram por um período, procriando com as habitantes de Lemnos. A segunda parada se deu na ilha de Samotrácia, onde foram iniciados nos mistérios dos Cabiros $^{3}$ para conseguir proteção contra naufrágios. Em seguida, os tripulantes de Argo pararam em Mísia, onde sofreram alguns contratempos, devido à sedução das ninfas; ao chegarem a Âmico, os viajantes foram surpreendidos pelo rei do local que fez um desafio ao jovem Pólux. O desafio era uma tradição entre os habitantes por ocasião da chegada dos visitantes à cidade. Pólux representou os companheiros, derrotou o rei e o fez prometer que jamais importunaria novos estrangeiros que chegassem ao local.

Após a aventura vivida em Âmico, os argonautas aportaram naTrácia, onde os jovens ajudaram ao rei Fineu a livrar-se de suas maldições: as Harpias que carregavam tudo que fosse colocado na frente do rei, inutilizando, por meio de seus excrementos, o que não podiam devorar. Os heróis as perseguiram e as fizeram prometer nunca mais importunar o rei. Em troca, poderiam permanecer vivas. Como recompensa, os argonautas receberam do rei orientações sobre como atravessar as Ciâneas, recifes que se fechavam violentamente antes da chegada ao destino da viagem.

As Argonáuticas se dividem em quatro livros, reunindo um total de 5836 hexâmetros, medida poética literária que consiste em seis pés métricos iguais por versos, nos quais os quatros primeiros pés podem ser dactílicos ou espondeus; o quinto, dáctilo, e o sexto, espondeu como na Ilíada. Estudos sobre As Argonáuticas afirmam ser uma obra épica anterior a Eneida de Virgílio. Também se afirma que ela pode ser comparada a llíada ou a Odisseia de Homero em tamanho e extensão. A obra tem, como um de seus momentos mais importantes, a captura de Medéia por Jasão. A moça possui poderes mágicos que permitirão que Jasão encontre o

\footnotetext{
${ }^{3}$ Os Cabiros eram filhos de Vulcano; era essa a opinião geralmente aceita, se bem que alguns autores os fizessem filhos de Júpiter ou de Prosérpina. Eles exploravam o feno, principalmente o de Samotrácia, mas trabalhavam em todos os metais. Talvez o seu culto tenha vindo do Egito, pois em Menfis eles tinham um templo; entretanto supõese que veio da Frigia. (FONTE?)
} 
Velocino de Ouro (livro III). Ao encontrar e tomar posse do Velocino, Jasão volta para sua terra pelos rios Danúbio e Pó, ambos em terras alemãs, Mar Mediterrâneo e Norte da África. Essa obra é, também, responsável por nos mostrar uma Medeia ainda doce, amorosa e apaixonada por Jasão, totalmente oposta àquela da tragédia de Eurípedes, em que Medeia mata os próprios filhos para vingar-se do marido traidor.

As Argonáuticas trazem muitas cenas impactantes, dentre as quais está a recusa dos argonautas em levar a deusa Pallas Athena em sua viagem e, a posteriori, receber não só Medeia, mas doze escravas que a acompanhavam quando ela decide ajudar Jasão a encontrar o Velo de Ouro. Outros elementos tornam a epopeia extremamente ligada à figura feminina, como os sonhos de Medeia, Circe e Eufemo, que mostraram as tramas pelas quais passaram Jasão e seus homens. Vê-se ainda uma cena rara: Medeia passa a ser argonauta por ocasião da morte de Absinto, algo notável para a cultura grega, visto que ali uma mulher passa a possuir status igual ao homem. Apesar de ser vista, por alguns estudos críticos, como uma macilenta imitação dos poemas homéricos, As Argonáuticas possuem características estilísticas e estruturais de relevante riqueza de conteúdo, além da versatilidade de Apolônio que se recusou a repetições monótonas dos poetas que o antecederam. Daí, ao contrário das visões que diminuem o valor da obra, ser possível reconhecer em Apolônio alguma inventividade.

Ao contar as peripécias pelas quais passaram os heróis liderados por Jasão, Apolônio nos dá uma nova visão de heróis como Hércules, que não aceitam os artifícios do amor utilizado por Jasão. Nesse momento, percebe-se que há uma diferenciação entre os heróis criados por Apolônio e os heróis criados por Homero; Jasão é um herói que se importa com a coletividade e não com a individualidade utilizada para descrever os heróis das epopeias homéricas.

Essas narrativas épicas foram passadas ao longo dos anos na Europa pela tradição oral e, na medida em que os europeus foram colonizando os povos das regiões às quais chegaram, levavam essas narrativas e as transmitiam aos habitantes das colônias, que, por sua vez, continuavam transmitindo-as de pai para filho por meio da oralidade.

Alguns escritores dizem que Apolônio escreveu uma história que, para Homero, já era antiga. Goldhill (1991) destaca que:

O conteúdo de seu grande poema, a Argonáutica, é a busca de Jasão pelo Velocino Dourado, e não apenas isso acontece na geração imediatamente anterior à da llíada de Homero - nós observamos o pequeno Aquiles vendo a partida de seu pai - mas, também, a história da Argo é expressamente mencionada em Homero como sendo uma canção bem conhecida (Od. XII, vv. 69-70). Apolônio volta a um tempo antes do de Homero para escrever - como se fosse para redescobrir - a história já antiga para Homero. E a consciência de Apolônio de seu status epigônico, sua manipulação dos artefatos culturais e linguísticos do passado, são cruciais para esse texto: seus jogos com a linguagem literária, sua confusão de expectativas genéricas, suas representações paródicas de figuras do passado, sua autoconsciência, têm de fato se tornado tópicos padrão na crítica recente da Argonáutica (GOLDHILL,1991, p.285). 
Percebe-se que Goldhill deixa claro que o poema de Apolônio traz uma nova marca literária que promove uma ruptura, isto é, traz renovação: trabalhar um tema de uma história muito antiga como forma de preservá-lo. Ora, se, tal como Apolônio, há uma preocupação com a preservação literária por parte de muitos autores, nota-se que a preservação de $A s$ Argonáuticas, em vários rincões do Brasil, se deu graças à oralidade que se fez presente como elemento fundamental, naqueles locais, para a sobrevivência do gênero épico. É notório que a preservação do gênero épico nas terras citadas não foi feita de maneira pensada, visto que, muitos não sabem o tesouro cultural que passam de geração a geração. Logo, o que permanece vivo no imaginário popular é a história em si, pela força mítica de seus componentes.

Vale ressaltar que a chegada dos portugueses às terras hoje pertencentes ao estado de Sergipe trouxe não só o comércio, mas, também, lendas e mitos para essa região. A Lenda do Velocino de Ouro que, nas terras da Serra do Canine, passou a ser chamada de Lenda do Carneiro de Ouro, ainda se faz presente nessa região nos dias atuais. Muitos moradores da sede, a cidade de Tobias Barreto, bem como dos povoados Jabeberi, Cancelão, Campestre do Abreu e Agrovila que foram fundados nas terras que compõem a Serra, ainda contam orgulhosos a lenda que a eles foi deixada de herança por seus ancestrais portugueses.

Ora, nos dias atuais, se faz necessário pensar em como a tradição oral mantém vivas "histórias" de uma tradição muito antiga em locais de difícil acesso, onde muitos de seus habitantes não tiveram sequer condições de ir à escola. No entanto, por meio das lendas que Ihes são contadas, mantiveram na memória de seus filhos maravilhas como As Argonáuticas de Apolônio de Rhodes, obra estudada nas mais renomadas Universidades mundo afora. Essas comunidades são responsáveis por preservar e manter viva, por meio da oralidade, a cultura épica trazida pelos portugueses durante a colonização do Brasil. Ainda que as informações referenciais sobre a obra de Apolônio não cheguem claramente a essas populações, o fato de a história Ihes ser muito familiar facilitaria e muito o desenvolvimento de atividades para levar às salas de aula, por exemplo, informações mais precisas e culturalmente mais amplas.

Na região em que a lenda é preservada, podemos notar o orgulho que o povo possui em manter a cultura herdada de seus antepassados de origem lusitana, e para que esse legado fosse preservado em uma população isolada, a oralidade teve participação fundamental , visto que foi a única fonte utilizada para que as futuras gerações pudessem conhecer a lenda oriunda das narrativas contadas pelos primeiros povos a habitar a Serra do Canine e imediações.

Vê-se, portanto, ser necessário demonstrar a importância da preservação da tradição oral e, ao mesmo tempo, observar como essas histórias são contadas por seus "guardiões" atemporais. Muitos dos contadores da Lenda do carneiro de Ouro reúnem-se à noite nas portas 
de suas casas para contar as aventuras de seus ancestrais, que saíam em busca das riquezas prometidas àqueles que fossem realmente corajosos para enfrentar as provas propostas pelo Carneiro de Ouro. Para que as histórias possam ser contadas, se faz necessário que haja uma plateia e que esta esteja atenta às histórias, garantindo, assim, que ela possa ser contada posteriormente aos futuros habitantes da Serra do Canine. Essa realidade pode ser vista nas explanações de Chevrier (1984) e Amrouche (1987), quando abordam a temática da oralidade nas literaturas africanas de língua francesa:

Segundo a tradição, a arte de contar é um dom e o contador um inspirado, um eleito. Por isso, existe todo um ritual envolvendo o ato de contar. Geralmente é à noite que as sessões de contos se realizam porque, além dos corpos e espíritos já estarem repousados, a noite favorece também a aproximação dos ancestrais mortos (CHEVRIER, 1984, p. 191).

E é através de uma fórmula mágica que o contador introduz seu público nesse "universo da lenda". Conforme explica Taos Amrouche , além da fórmula inicial, sua mãe usava uma outra para concluir os contos - "Mon conte est comme un ruisseau, je la 'i conté à des Seigneurs " indicando, assim, que "o conto devia prosseguir seu curso de boca em boca, de alma em alma, até o final dos tempos" (AMROUCHE, 1987, p. 10).

Nota-se que a oralidade tem uma importância inestimável, mesmo que não seja intencional, na divulgação de obras que são acessíveis apenas àqueles que recebem instrução acadêmicas. Dessa maneira, é importante buscar a valorização da oralidade como instrumento de acesso de camadas populacionais menos privilegiadas à própria literatura. Ora, Tzevtan Todorov (2009), ao falar que literatura está em perigo devido à forma como está sendo apresentada aos jovens, supõe que essa realidade possa ser mudada se pudermos, através da oralidade, seduzir os jovens para que estes possam se identificar com os elementos clássicos que façam parte de sua realidade. Como bem diz Antonio Candido (2004), a literatura se manifesta universalmente através do ser humano, e, em todos os tempos, tem função e papel humanizador, logo, ela precisa estar acessível a todos e não apenas a um pequeno fragmento da sociedade. Pautada por essas reflexões, discorro um pouco sobre a tradição da Lenda do Carneiro de Ouro em Tobias Barreto.

\section{As Argonáuticas em Tobias Barreto}

Foi através dos portugueses que a Vila de Campos do Rio Real, atual Tobias Barreto, teve contato com as crenças, mitologia e costumes do povo português e também de costumes e histórias de outros povos que se incorporaram à cultura portuguesa. Dentre as muitas histórias mitológicas que povoaram a imaginação do povo português, está o mito do "Velocino de Ouro", oriundo da epopeia grega As Argonáuticas ou Os Argonautas, de Apolônio de Rhodes. O povo 
português que chega com Belchior Dias Moreira, O Moreia, às terras tobienses, traz consigo a história mítica que se faz presente ainda nos dias atuais nos povoados Jabeberi, Cancelão, Agrovila e Campestre do Abreu, que foram fundados na Serra do Canine, bem como na própria sede, a cidade de Tobias Barreto.

Reza a lenda que, em noites de lua cheia, a serra do Canine fica iluminada por um forte "halo" deluz. Certa feita, um jovem curioso foi até a serra em dia de lua cheia para descobrir o mistério por trás da luz que todos viam de longe. Ao chegar perto do local que emanava a luz brilhante, ele encontrou um carneiro de ouro, que, ao vê-lo, saiu em disparada pela serra, iluminando tudo ao redor. O rapaz, assustado, voltou para casa e chamou o pai para ver sua descoberta. Quando chegam até o local, não havia mais nenhum carneiro, pois a lenda é específica: só poderão ver o Carneiro de Ouro e ter acesso a seu tesouro os puros de coração! E estes devem ser capazes de passar pelas provas apresentadas pelo Carneiro de Ouro. Com o passar dos anos, muitos juram ter visto o Carneiro de Ouro da Serra do Canine, mas nenhuma pessoa parece ter sido digna de obter a riqueza que ele possui, ou não teve êxito nas duras provas exigidas por ele.

A história trazida pelos portugueses foi, através dos tempos, sendo passada de pai para filho através da oralidade e, graças a essas contações de história ao pé da calçada e terreiros, é que se manteve viva a "Lenda do Carneiro de Ouro" da Serra do Canine. Durante anos, a população encarregou-se de passar adiante o mito do Carneiro de Ouro. Não há uma criança ou jovem na cidade de Tobias Barreto e regiões circunvizinhas da Serra do Canine que tenha um avô ou uma avó com mais de sessenta anos que nunca the tenha contado histórias e que não saiba da existência desse Carneiro de Ouro, que aparece em noite de lua cheia e deixa um rastro de luz na Serra do Canine.

No decorrer dos tempos, uma das formas mais antigas de se conhecer histórias foi a oralidade. A história ouvida pela avó, cuja bisavó contou-lhe e que hoje sua mãe the conta é um bom exemplo da eficácia existente nesta prática. Não se ter nenhum registro escrito, não haver uma estante onde se possa pegar um diário e ler em voz alta histórias de centenas de anos atrás, torna-se algo que não nos faz apagar o desejo de ter conhecimento sobre o que a oralidade conta. Pelo contrário, muitas vezes essas histórias nos impulsionam a saber mais. Assim, através do conhecimento e do encantamento transmitidos pela oralidade de mitos, contos, ritos e ensinamentos descritos à noite à beira da calçada ou no terreiro de um sítio, outros caminhos para se adquiri conhecimentos são criados. Talvez, muitas pessoas, naquela época em que a bisavó, que sequer sabia ler e escrever, mas que nem por isso faltava as palavras para "expor" suas histórias ouvidas e repassadas por gerações aos futuros perpetuadores da tradição oral, tivessem conhecimento da importância dessa contação de histórias e de como elas ajudariam a 
manter vivas, em nossa sociedade, histórias épicas espetaculares de que são exemplo As Argonáuticas.

Na obra História da Epopeia Brasileira (Das origens ao século XVIII, 2015), Anazildo Vasconcelos da Silva e Christina Ramalho deixam claro que:

Não é, assim, por acaso que se dá resgate da tradição épica, já que a epopeia, preservando a memória ancestral das narrativas míticas da tradição oral, se apresenta, no curso da literatura ocidental, como a forma poética adequada para celebrar e perpetuar a identidade heroica de um povo da divulgação das conquistas de seus heróis (SILVA; RAMALHO; 2015, p. 29).

Muito do que se sabe e se quer perpetuar não necessita da letra/escrita, mas sim da palavra/falada e, esta palavra falada, por sua vez, ganha força e é levada por aqueles que a ouvem e a posteriori a transmitem. A tradição oral tem a função de preservar histórias, de garantir às novas gerações o conhecimento daquilo que seus antepassados lhes legaram como fonte cultural. Em algumas culturas essa parte da tradição é um legado que está sob a responsabilidade dos mais velhos, que, através das histórias que contam, tornam viva a cultura de seu povo. Para muitos grupos, inclusive, a oralidade é a única forma de resgatar e preservar sua ancestralidade. Ferreira (2010) nos faz perceber esta realidade:

Há os estudiosos ou apreciadores que segmentam e assumem, por exemplo, o campo literário como um todo de fronteiras rígidas, apegando-se a uma certa fixidez e até, por hábito, preferem chamar para literatura qualquer outra coisa que pareça fugir ao padrão estabelecido pela instituição "Literatura" ou, no polo oposto, aquilo o que não caiba nos domínios legitimados de uma cultura popular tradicional que se costuma delimitar enquanto Folclore, por sua vez, matéria tornada nobre e justificada. Há, no entanto, quem considere, e que despreze mesmo esses textos de cultura, por não lhes encontrar valor (FERREIRA, 2010, p. 12).

Uma coisaé certa: a língua falada "éde todos",éatravés dela que clássicos literários podem chegar aos ouvidos daqueles que não tiveram a oportunidade de ser escolarizados; é através dela que todos podem ser iguais.

No caso dos habitantes da Serra do Canine, em especial os moradores dos Povoados: Jabeberi, Cancelão, Campestre do Abreu e Agrovila, a oralidade teve uma função fundamental para a preservação das histórias contadas desde a vinda dos portugueses que, juntamente com os negros e índios, ajudaram na formação da cidade de Tobias Barreto. Graças à oralidade é que, portanto, uma versão popular e reduzida de As Argonáuticas chegou a inúmeros tobienses. $\mathrm{Na}$ Lenda do Carneiro de Ouro, Jasão e o Velocino de Ouro ganharam uma nova roupagem, mas essa versão minimizada foi responsável por fazer inúmeras crianças buscarem leituras. No entanto, apesar do grande valor da oralidade, apenas a língua escrita tem status importante no âmbito escola. Muitas vezes, deixa-se de lado a oralidade e sua responsabilidade de manterem vivos textos clássicos da literatura mundial, ainda que os referentes diretos não sejam trazidos 
pelos oradores. Podemos notar esta desqualificação da oralidade em Fares (2010) quando diz que:

[...] desqualificar este objeto é desconsiderá-lo como texto fundador, a origem de todos os outros [...]. As poéticas orais fazem parte do universo cultural dos discentes, sobretudo os moradores da zona rural do Brasil, das zonas periféricas das grandes cidades, e os que (con)viveram nesses territórios ou com seus habitantes. Trazer esta realidade para o sistema de ensino, estabelecer relações de trocas simbólicas é um dos sentidos da educação. Por isso, a discussão deve também pertencer aos cursos de letras, ao ensino fundamental e ao médio (FARES, 2010, p. 265-266).

Muito do que se fala sobre a oralidade nos faz perceber como essa prática ajudou na preservação do cabedal cultural não só da nação onde a trama da história se passa, mas, também, daqueles de onde são originárias. Aqui no Brasil, ter contato com as narrativas que circulam na forma de oralidade nos faz perceber como essas narrativas foram levadas nas viagens de circunavegação e, a posteriori, trazidas para cá, durante o processo de colonização. Na caso tobiense, em especial, nota-se que narrativas associadas ao mito do Velocino de Ouro No contexto tobiense, percebe-se que a oralidade teve uma participação primordial na conservação da história épica dos argonautas nas terras que compõem a atual cidade de Tobias Barreto, e isso se deu graças aos moradores das imediações do Canine que trazem consigo o conhecimento da "lenda".

\section{Considerações finais}

Ao longo dos anos, a narrativa de Apollônio de Rhodes, trazida para o Brasil, em especial para as terras colonizadas por Belchior Dias Moreira, o "Moreia", foi passada de pai para filho nos arredores da Serra do Canine e, consequentemente, trazida para a então Vila de campos do Rio Real por aqueles que tentaram uma vida nova na Vila de Campos que depois tornou-se a cidade de Tobias Barreto. A narrativa escrita há séculos ainda ressoa em alto e bom som através da oralidade nos povoados Jabeberi, Cancelão, Campestre do Abreu e Agrovila e na sede: a cidade de Tobias Barreto. A "Lenda do Carneiro de Ouro" traz similaridades evidentes com As Argonáuticas, o que deixa claro que a epopeia fora trazida para as terras tobienses por seus colonizadores, os portugueses.

Vimos que muitos legados deixados pelos colonizadores assim o foram através da oralidade, e muito do que se guardou na memória popular está vivo graças a esta realidade que se tornou necessária em terras tobienses devido ao alto índice de analfabetismo existente até o final da década de oitenta nas comunidades que circundam a Serra do Canine. Outrossim, notase que, apesar de todas as dificuldades passadas por estes sertanejos, eles mantiveram-se firmes em manter um legado passado de geração em geração. 
Conclui-se, então que graças à oralidade, a tradição épica mantém-se viva e em atividade nos lugares mais remotos do Brasil. A epopeia, como narrativa e fonte de aventuras e misticismo, ajuda a manter vivos os ideais de grandiosidade que o herói épico instiga em quem conhece a epopeia. A narrativa épica que inspirou a Lenda do Carneiro de Ouro da Serra do Canine pode não ser conhecida como deveria pelo povo tobiense, mas, graças à oralidade, o cidadão tobiense pode ter acesso à principal imagem mítica trazida por um dos clássicos da literatura mundial, As Argonáuticas, de Apolônio de Rhodes. Por isso, o sertanejo que habita as terras íngremes do Campestre do Abreu e que, em dias de chuva, não consegue descer a Serra do Canine para realizar suas atividades de pastoreio, e todos os sertanejos do Jabeberi, Cancelão e Agrovila entram em contato com a imagem mítica do herói que, por meio de seu obstinado enfrentamento de obstáculos e alimentado por intenções puras, consegue alcançar seus propósitos e enriquecer sua vida.

\section{Referências bibliográficas}

AMROUCHE, M. T. Le grain magique: contes, poèmes, proverbes berbères de Kabylie. Paris: Maspéro, 1966; Paris: La Découverte, 1987

APOLLONIO DE RHODES. Argounautiques, Texte établi et commentê par Francis Vian et Traduit par Émile Delage. Paris: Les Belles Lettres,1976.

CANDIDO, A. O direito à literatura, In: CANDIDO, Antônio. Vários escritos. 4a ed. São Paulo: Duas cidades; Rio de Janeiro: Ouro sobre azul. 2004.

CHEVRIER, J. Littérature nègre. Paris: Armand Colin, 1984.

FARES, Josebel Akel. Oralidade e educação. Poéticas orais em sala de aula: relatos e retratos. In: Anais do Seminário brasileiro de poéticas orais: vozes, performances, sonoridades I. Londrina: Universidade Estadual de Londrina - UEL, 2010. p. 264 - 279.

GOLDHILL, S. The poet's voice: Essays on poetic and greek Literature. Cambridge: Cambridge University Press, 1991.

SILVA, A. V.; RAMALHO, C. História da Epopeia Brasileira Das Origens ao Século XVIII. Editora. Art Ner Comunicação: Aracaju, 2015.

MAUSS, M. Sociologia e Antropologia. Trad. de Paulo Neves. São Paulo: Cosac \& Naify, 2003.

TODOROV, T. A literatura em perigo. Rio de Janeiro: DIFEL, 2009. 